\title{
Violences et mémoire en Amérique latine
}

Raynald Belay, Jorge Bracamonte, Carlos Iván Degregori et Jean Joinville Vacher (éds), Memorias en conflicto. Aspectos de la violencia politica contemporanea, Lima, Institut français d'études andines (IFÉA)/Instituto de Estudios Peruanos, 2004, 349 p.

\section{Gilles Bataillon}

\section{CpenEdition \\ Journals}

Édition électronique

URL : http://journals.openedition.org/transcontinentales/1476

DOI : 10.4000/transcontinentales. 1476

ISBN : 978-2-8218-1408-0

ISSN : 1775-397X

Éditeur

Editions de la maison des sciences de l'homme

\section{Édition imprimée}

Date de publication : 30 juin 2006

Pagination : 184-185

ISBN : 2200-92169-1

ISSN : 1950-1684

Référence électronique

Gilles Bataillon, «Violences et mémoire en Amérique latine », Transcontinentales [En ligne], 2 | 2006, document 18, mis en ligne le 15 décembre 2012, consulté le 25 septembre 2020. URL : http://

journals.openedition.org/transcontinentales/1476; DOI : https://doi.org/10.4000/transcontinentales. 1476

Ce document a été généré automatiquement le 25 septembre 2020.

Tous droits réservés 


\section{Violences et mémoire en Amérique latine}

Raynald Belay, Jorge Bracamonte, Carlos Iván Degregori et Jean Joinville Vacher (éds), Memorias en conflicto. Aspectos de la violencia politica contemporanea, Lima, Institut français d'études andines (IFÉA)/Instituto de Estudios Peruanos, 2004, 349 p.

\section{Gilles Bataillon}

\section{RÉFÉRENCE}

RAYNALD Belay, JoRgE Bracamonte, CARLOS IVÁN Degregori ET JEAN Joinville Vacher (ÉDS), Memorias en conflicto. Aspectos de la violencia politica contemporanea, Lima, Institut français d'études andines (IFÉA)/Instituto de Estudios Peruanos, 2004, 349 p.

1 Fruit de deux colloques organisés par des institutions françaises et péruviennes, Memorias en conflicto; aspectos de la violencia politica contemporanea réunit différentes études sur les expressions de la violence contemporaine et plus spécifiquement sur le regard porté par les latino-américains et les sud-africains sur les dictatures militaires, les guerres internes comme sur l'expérience de l'apartheid. Le propos de l'ensemble de ces auteurs n'est pas de faire le récit de ces moments où la violence fut non seulement une modalité concrète de l'action de l'État et des différents groupes sociaux, mais aussi une relation fondamentale à ce qui apparaissait comme barbarie en marge du social, ou menaçant celui-ci. Toutes ces interrogations portent d'une façon ou d'une autre sur les mises en sens de cette violence dans des contextes désormais marqués par l'avènement de régimes démocratiques tant en Amérique latine qu'en Afrique du Sud.

2 Jorge Deustua, Miguel Giusti, Sandrine Lefranc, Salomón Lerner, Yves Michaud, Olivier Mongin, Beatrice Pouligny et Jacques Semelin s'interrogent ainsi de façon comparative sur ces phénomènes en les lisant au regard des réflexions sur les totalitarismes européens du $\mathrm{Xx}^{\mathrm{e}}$ siècle, telles celles trop oubliées de Karl Jaspers ou de Hannah Arendt, 
ou de l'histoire de massacres emblématiques de l'histoire européenne, comme la Saint Barthélemy.

3 Les autres auteurs optent au contraire pour des réflexions centrées sur des cas nationaux, parfois envisagés à l'échelle microsociologique. Ainsi, Carlos Iván Degregori, Norma Fuller, Eduardo González, Efraín Kristal, Gonzalo Portocarrero, s'interrogent sur l'expérience de la guerre qui opposa le Sentier lumineux à l'État et à la société au Pérou, sur le travail de mise en mémoire qui fut celui de la Commission de la Vérité et de Réconciliation en Afrique du Sud, comme sur celui interne aux différentes communautés rurales affectées par la violence. Norma Fuller, Daniel Pécaut et Gonzalo Sánchez cernent la spécificité des expériences colombiennes. Tous trois mettent en relief la singulière difficulté à donner sens à une succession de guerres internes opposant guérillas, forces armées et groupes paramilitaires depuis maintenant deux décennies. Ces trois auteurs discernent le signe de cette difficulté à donner sens aux événements dans les chassés-croisés qui s'opèrent entre des mémoires ô combien subjectives des événements et certains récits historiques.

4 Du coup les mémoires font leurs certaines constructions historiques partisanes, peu soucieuses de distanciation et d'objectivation, et s'appuient sur celles-ci pour organiser des récits cohérents, tandis qu'historiens et sociologues collent trop souvent à la subjectivité des récits des acteurs et se refusent à tout travail de prise de distance critique. Jean Louis Déotte et Patricia Valdez s'attachent à cerner le sens de la place des commémorations des disparitions en Argentine, tandis que Gustavo Buntinx, Lydia Liberge et Juan Ramón Quintana s'interrogent respectivement sur la mémoire de la violence au Chili, en Afrique du Sud et en Bolivie.

5 L'intérêt de cet ouvrage ne tient pas seulement à l'attrait que peut susciter un champ de la recherche, la Mémoire, devenu depuis plus d'une décennie fort à la mode. Il tient à sa capacité à éclairer l'histoire et la sociologie de l'Amérique latine comme de l'Afrique du Sud d'un jour nouveau. En effet, ces pays se sont longtemps organisés et pensés autour de principes et de modes d'action aux antipodes de ceux qui prévalaient dans le monde démocratico-libéral. Le social n'y était pas reconnu comme voué à la division et traversé par des antagonismes légitimes et pour une part insurmontables dont il convenait d'organiser la représentation de façon à parvenir à une conciliation des intérêts et des différends à la fois juste et productrice d'un bien commun. L'intervention de l'État se faisait au nom de la désorganisation du social, il se devait d'être une puissance instituant la société « par en haut ». L'idée de division renvoyait à l'idée d'un inévitable chaos pour peu que l'on n'encadre pas les classes subalternes.

6 Comme l'a montré Daniel Pécaut dans le contexte latino-américain, l'Ordre et la Violence furent longtemps les catégories centrales du politique. Or l'ensemble de ces réflexions sur le passé, qu'il s'agisse des formes prises par la mémoire collective ou des formes de la mise en récit historique, montrent bien le versant politique de ces politiques de la mémoire et de l'histoire. Elles sont parties prenantes de l'institution d'un monde nouveau où la Violence et l'Ordre ne sont plus l'alpha et l'oméga du vivre ensemble, mais commencent au contraire à être jugées comme le signe même de cette barbarie que l'on entendait naguère combattre.

7 C'est dire que quelles que soient les limites de certaines mises en formes de la mémoire, leur oubli de certains pans de l'histoire comme de certains faits, quelles que soient certaines volontés d'amnistier bon nombre de crimes commis durant l'époque de 
l'apartheid sud-africain ou durant les guerres internes latino-américaines, se fait jour un rapport nouveau à la violence dans l'ensemble de ces pays.

\section{AUTEURS}

\section{GILLES BATAILLON}

Université de Caen - Centre d'étude des mouvements sociaux (CEMS) EHESS 